\title{
Prognostic factors affecting local control of hepatic tumors treated by stereotactic body radiation therapy
}

Sylvain Dewas ${ }^{1,3^{*}}$, Jean-Emmanuel Bibault ${ }^{1}$, Xavier Mirabel ${ }^{1}$, Ingrid Fumagalli ${ }^{1}$, Andrew Kramar $^{2}$, Hajer Jarraya ${ }^{3}$, Thomas Lacornerie ${ }^{1}$, Claire Dewas-Vautravers ${ }^{1}$ and Eric Lartigau ${ }^{1}$

\begin{abstract}
Purpose: Robotic Stereotactic Body Radiation Therapy with real-time tumor tracking has shown encouraging results for hepatic tumors with good efficacy and low toxicity. We studied the factors associated with local control of primary or secondary hepatic lesions post-SBRT.

Methods and materials: Since 2007, 153 stereotactic liver treatments were administered to 120 patients using the CyberKnife ${ }^{\oplus}$ System. Ninety-nine liver metastases (72 patients), 48 hepatocellular carcinomas (42 patients), and six cholangiocarcinomas were treated. On average, three to four sessions were delivered over 12 days. Twenty-seven to 45 Gy was prescribed to the $80 \%$ isodose line. Margins consisted of 5 to $10 \mathrm{~mm}$ for clinical target volume (CTV) and $3 \mathrm{~mm}$ for planning target volume (PTV).

Results: Median size was $33 \mathrm{~mm}$ (range, 5-112 mm). Median gross tumor volume (GTV) was $32.38 \mathrm{~cm}^{3}$ (range, $0.2-499.5 \mathrm{~cm}^{3}$ ). Median total dose was $45 \mathrm{~Gy}$ in three fractions. Median minimum dose was $27 \mathrm{~Gy}$ in three fractions. With a median follow-up of 15.0 months, local control rates at one and two years were $84 \%$ and $74.6 \%$, respectively. The factors associated with better local control were lesion size $<50 \mathrm{~mm}(p=0.019)$, GTV volume $(p<0.05)$, PTV volume $(p<0.01)$ and two treatment factors: a total dose of 45 Gy and a dose-per-fraction of 15 Gy $(p=0.019)$.

Conclusions: Dose, tumor diameter and volume are prognostic factors for local control when a stereotactic radiation therapy for hepatic lesions is considered. These results should be considered in order to obtain a maximum therapeutic efficacy.
\end{abstract}

Keywords: Hepatocellular carcinoma, Liver metastases, SBRT, Local control, Prognostic fractors

\section{Introduction}

Stereotactic body radiation therapy (SBRT) for hepatic metastases (HM) and hepatocellular carcinoma (HCC) has shown encouraging rates of local control and low toxicity [1-4]. Many patients with primary or secondary hepatic lesions can now be treated with these new techniques. However relevant data and studies are still required to define which patients will benefit best from it and which fractionation regimen and total dose should

\footnotetext{
* Correspondence: s-dewas @o-lambret.fr

${ }^{1}$ Academic Radiation Oncology Department \& University Lille II, CLCC Oscar Lambret, 3 rue Frederic Combemale, BP 307, Lille cedex 59 020, France ${ }^{3}$ Department of Radiology, CLCC Oscar Lambret, 3 rue Frederic Combemale, BP 307, Lille cedex 59 020, France

Full list of author information is available at the end of the article
}

be used. Unfortunately, the published series are heterogeneous for the doses used as well as the number of patients treated and do not allow for reliable analysis. Since July 2007, a CyberKnife System (Accuray Incorporated, Sunnyvale, California, U.S.A.) has been available in our department. This image-guided system delivers hypofractionated robotic SBRT. Herein, we present our results for 153 primary or secondary hepatic lesions treated with SBRT and the factors associated with tumor control.

\section{Materials and methods \\ Patients \\ Between July 2007 and March 2010, 120 patients under- went SBRT with real-time tracking for primary or}

\section{Biomed Central}


secondary hepatic lesions. Seventy-two patients were treated for HM, 42 for HCC (36 patients with A and 6 patients with B Child-Pugh score) and six for cholangiocarcinoma (CC).

Patients with HM were ineligible for hepatic surgery or radiofrequency ablation. Other selection criteria for $\mathrm{HM}$ were WHO score under 3, four or less hepatic lesions and lesion size under $100 \mathrm{~mm}$. For $\mathrm{HCC}$, selection criteria were WHO score under 3 , two or less lesions, Child-Pughs score A or B. For cholangiocarcinoma, selection criteria were WHO score under 2 and target size under $120 \mathrm{~mm}$. SBRT is considered for patients for whom standard treatments such as resection, transplantation, chemoembolization or radiofrequency ablation were not feasible. Informed consent was obtained in accordance with the guidelines of the French National Cancer Institute (Institut National du Cancer) required when assessing the efficacy and toxicity of a novel therapy,

All treatments were delivered with the CyberKnife system, at the Academic Department of Radiotherapy, Centre Oscar Lambret, Lille. The population treated by SBRT for hepatic tumors consisted of 120 patients (78 men and 42 women). The average age was 65 years (range, 23 to 85 years). There were a total of 153 tumors; 97 patients had one, 15 patients two, six patients three, and two patients had four tumors treated. The median diameter of a tumor was $33 \mathrm{~mm}$ (range, 5 to $112 \mathrm{~mm}$ ). The median volume of GTV was $32.38 \mathrm{~cm}^{3}$ (range, 0.2 to $499.5 \mathrm{~cm}^{3}$ ).

\section{Planning and treatment}

The outpatient treatments were conducted using the Multiplan $^{\bullet}$ v3 treatment planning software (Accuray) and the Synchrony ${ }^{\circ}$ Respiratory Tracking System (Accuray), enabling the tracking of tumor movement in real time. Gold markers (fiducials) were implanted around the lesion before the planning CT. Three to four fiducials are implanted close to the target by a radiologist with a CT scan while the patient is under local anesthesia. The median time between fiducial implantation and the beginning of the treatment was 29 days (minimum seven days). A triphasic (arterial phase, portal phase, and late phase) planning CT scan was recorded twice with $50 \mathrm{cc}$ of iodinated contrast agent, 1- and 3$\mathrm{mm}$ slice thickness with the patient lying on a vacuum mattress or a self-expanding foam mattress. Gross Tumor Volume (GTV) was based on the better of either the contrast-enhanced planning CT or MRI, depending on image quality. Clinical Target Volume (CTV) was $5 \mathrm{~mm}$ geometric expansion of the GTV (CTV = GTV + $5 \mathrm{~mm}$ ) to treat any microscopic disease extension. The margin was $1 \mathrm{~cm}$ within the liver, and none outside, in cases of HCC and CC. Planning Target Volume (PTV) contained the CTV and a 3-mm geometric margin to account for the uncertainty secondary to the slice thickness. Two weeks were usually necessary between dosimetric CT and start of treatment. The prescribed dose was 45 Gy for HCC. Early HM cases received 40 Gy in four equal fractions; then the dose was increased to 45 Gy in three equal fractions, as in the cases of HCC. Dose constraints are shown in Table 1. Doses slightly varied based on the location of the tumor and the nearby organs at risk. Normal tissue constraints used for liver lesions included the volume receiving 21 Gy $(\mathrm{V} 21<33 \%)<33 \%$ and $\mathrm{V} 15<50 \%$ for normal liver. If this constraint was not possible, dose was decreased. The dose was prescribed to the $80 \%$ isodose line (95\% of the PTV receiving the total dose) and delivered in an average of eight days (range, four to 17 days).

\section{Follow-up}

All patients had a contrast-enhanced CT scan of the thorax, abdomen, and pelvis, and a hepatic MRI when it was available, at the time of treatment. Imaging was repeated at each follow-up every three months in addition to the clinical examinations and biochemical tests. Evaluations took into account changes in tumor vascularization, as recommended by EASL (European Association for the Study of the Liver) [5]. Local response was considered complete in case of disappearance of the target lesion or its replacement by fibrotic scar not changing in size or partial when at least a 30\% decrease in the largest diameter of the target was observed. Failure was defined as an increase of at least $20 \%$ in the size of the largest axis of the target. Absence of any of the above was considered stable disease including any changes in vascularization determined by contrast intake. Local control was imaging-based absence of progression. Follow-up was defined has the time between last treatment session and last evaluation.

\section{Statistics}

The software STATA v11 (Stata Corporation, College Station, Texas, USA) was used for the statistical analyses.

Table 1 Dose constraints (for 3 to 4 fractions)

\begin{tabular}{ll}
\hline Organ & Dose constraints \\
\hline Liver & V21 $<33 \%$ \\
\hline Spinal cord & Dmax $<22 \mathrm{~Gy}$ \\
\hline Kidney & $\mathrm{V} 15<33 \%$ \\
\hline Stomach & $\mathrm{V} 21<5 \mathrm{~cm}^{3}$ \\
\hline Duodenum & $\mathrm{V} 15<5 \mathrm{~cm}^{3}$ \\
\cline { 2 - 2 } & $\mathrm{Dmax}<24 \mathrm{~Gy}$ \\
\hline Small intestine & $\mathrm{V} 16<5 \mathrm{~cm}^{3}$ \\
\hline
\end{tabular}


Time to local failure was defined from the beginning of the treatment (as opposed to first diagnosis) until progression. Rates were estimated using the Kaplan-Meier method. Differences among survival curves were compared using the log-rank test. The univariate analyses of local control were performed using the Cox regression model. Fisher exact test and Pearson chi-squares methods were used to study the association between categorical variables, and the Kruskal-Wallis test for continuous variables. The Pearson correlation coefficient was used to assess the association between two quantitative variables. A p value $<0.05$ was chosen as the significance threshold.

\section{Results}

\section{Patient and treatment characteristics}

Patient characteristics are shown in Table 2. Median tumor diameter was $33 \mathrm{~mm}$ (range, 5 to $112 \mathrm{~mm}$ ); median GTV was $32.38 \mathrm{~cm}^{3}$ (range, 0.2 to $499.5 \mathrm{~cm}^{3}$ ) and median hepatic volume was $1,606 \mathrm{~cm}^{3}$ (range, 843 to $2,940 \mathrm{~cm}^{3}$ ). Dosimetric and technical data are presented in Table 3. Mean session length was 107 minutes (range, 36 to 199 minutes); average number of beams per treatment was 152 (range, 25 to 276 beams); median total dose was $45 \mathrm{~Gy}$ (15 Gy per session); the lowest total dose was 27 Gy ( 9 Gy per session); median followup was 15.0 months (CI 95\%: 12.4 to 17.5 months).

\section{Local control}

Twenty-two patients showed progression of one or more treated lesions (18.3\%). Three patients with HCC (7.3\% of HCC cohort), 17 patients with HM (25.4\% of HM cohort) and two patients with cholangiocarcinoma (33.3\% of CC cohort) experienced failures. Median time to recurrence for HCC patients was 3.71 months, compared to 6.74 months for $\mathrm{HM}$ and 13.6 months for $\mathrm{CC}$ $(p=0.075)$. Overall one and two-year local control rates regardless of pathology were $80.4 \%$ (CI $95 \%$ : $70.1 \%$ to $87.5 \%$ ) and $72.5 \%$ (CI 95\%: 60.2 to $81.6 \%$ ) respectively. For HCC the estimated local control rates at one and two years were $90.5 \%$. For HM, the one and two year local control rates were $73.3 \%$ and $67.4 \%$, respectively. Based on the number of tumors, among the 153 lesions $(99 \mathrm{MH}$, $48 \mathrm{HCC}$, and six CC tumors) four HCC tumors (8.7\%), 19 HM tumors (20.2\%), and two CC tumors (33.3\%) progressed at a median 3.7 months, eight months, and 13.6 months, respectively (Figure 1). The local control rate regardless of pathology was $83.7 \%$. Local control rates regardless of primary at one and two years were $84 \%$ (CI 95\%: $75.6 \%$ to $89.7 \%$ ) and $74.6 \%$ (CI $95 \%: 63.7 \%$ to $82.7 \%$ ), respectively. For HCC, the rate was $88.9 \%$ at both one and two years (CI 95\%: 72.5 to 95.8\%); for HM, these rates are 80.9\% (CI 95\%: 69.7 to $88.3 \%$ ) at one year and $72.5 \%$ at two years (CI 95\%: 59.3 to 82\%). For CC, local control rate were $100 \%$ at one year and two-year follow-up was not reached. Median survival without local recurrence was not reached.

Table 2 Patient characteristics

\begin{tabular}{|c|c|c|c|c|c|}
\hline & $\begin{array}{l}\text { Total N (\%) or } \\
\text { Median (range) }\end{array}$ & Hepatocarcinoma & Hepatic metastases & Cholangiocarcinoma & $\mathbf{p}^{*}$ \\
\hline \multicolumn{6}{|l|}{ Sex } \\
\hline Male & $78(65 \%)$ & $32(76.2 \%)$ & $42(58.3 \%)$ & $4(66.7 \%)$ & 0.14 \\
\hline Female & $42(35 \%)$ & $10(23.8 \%)$ & $30(41.7 \%)$ & $2(33.3 \%)$ & \\
\hline Age & $67(23-85)$ & $69(43-85)$ & $64(23-83)$ & $70(62-78)$ & 0.16 \\
\hline Weight (kg): & $78(43-120)$ & $83(47-120)$ & $74.5(43-115)$ & $73(68-85)$ & 0.07 \\
\hline BMI & $26.1(14.2-43.3)$ & $29(20.5-40.6)$ & $25.6(14.2-43.3)$ & $27.1(23.5-32)$ & 0.03 \\
\hline \multicolumn{6}{|l|}{ WHO } \\
\hline 0 & $92(77.3 \%)$ & $31(73.8 \%)$ & $58(81.7 \%)$ & $3(50 \%)$ & \\
\hline 1 & $23(18.5 \%)$ & $11(26.2 \%)$ & $9(12.7 \%)$ & $2(33.3 \%)$ & 0.08 \\
\hline 2 & 4 (3.4\%) & 0 & $3(4.2 \%)$ & $1(16.7 \%)$ & \\
\hline 3 & $1(0.8 \%)$ & 0 & $1(1.4 \%)$ & 0 & \\
\hline Prior treatments & $114(95 \%)$ & $19(45.2 \%)$ & $66(91.7 \%)$ & $3(50 \%)$ & $<0.001$ \\
\hline Radiofrequency & $11(9.2 \%)$ & $2(4.8 \%)$ & $9(12.5 \%)$ & 0 & 0.38 \\
\hline Surgery & $31(25.8 \%)$ & $4(9.5 \%)$ & $24(33.3 \%)$ & $3(50 \%)$ & 0.003 \\
\hline Chemo-embo & $8(6.7 \%)$ & $6(14.3 \%)$ & $2(2.8 \%)$ & 0 & 0.11 \\
\hline Radiotherapy & $2(1.7 \%)$ & $1(2.4 \%)$ & $1(1.4 \%)$ & 0 & 0.87 \\
\hline Chemotherapy & $62(51.7 \%)$ & $6(14.3 \%)$ & $54(75 \%)$ & $2(33.3 \%)$ & $<0.001$ \\
\hline Hepatic volume $\left(\mathrm{cm}^{3}\right)$ & $1548(843-2940)$ & $1614(908-2611)$ & $1499(843-2940)$ & $1783(1607-2018)$ & 0,19 \\
\hline Targets size (Sum in $\mathrm{mm}$ per patient) & $45(8-159)$ & $40(17-145)$ & $45(8-159)$ & $63(36-112)$ & 0,24 \\
\hline
\end{tabular}

${ }^{*}$ Chi-square/Fisher exact or Kruskal-Wallis. 
Table 3 Treatment characteristics

\begin{tabular}{|c|c|c|c|c|c|}
\hline & $\begin{array}{l}\text { Total N (\%) or } \\
\text { Median (range) }\end{array}$ & Hepatocarcinoma & Hepatic metastases & Cholangiocarcinoma & $\mathrm{p}^{*}$ \\
\hline Sum of GTV volumes $\left(\mathrm{cm}^{3}\right)$ & $32.9(0.2-499)$ & $47.5(1.4-499)$ & $25.6(0.2-245)$ & $261(8-371)$ & 0.029 \\
\hline Ratio of the volume of GTV to the Liver & $0.02(0-0.32)$ & $0.03(0-0.3)$ & $0.02(0-0.2)$ & $0.1(0-0.2)$ & 0.028 \\
\hline Ratio of the volume of PTV to the Liver & $0.08(0-0.38)$ & $0.09(0-0.38)$ & $0.05(0-0.37)$ & $0.2(0-0.3)$ & 0.074 \\
\hline Session length (min) & 107 (35-199) & $107(35-156)$ & $107(41-199)$ & $100(74-151)$ & 0.831 \\
\hline Number of beams (median) & $150(25-276)$ & $148(29-254)$ & $149(25-276)$ & $182(105-226)$ & 0.449 \\
\hline \multirow[t]{7}{*}{ Total dose (Gy) } & $45(27-45)$ & $45(27-45)$ & $45(27-45)$ & $45(29-45)$ & 0.321 \\
\hline & & - 45 Gy: 15 Gy x 3 & - 45 Gy: 15 Gy x 3 & - 45 Gy: 15 Gy x 3 & \\
\hline & & - 39 Gy: 13 Gy x 3 & - 40 Gy: 10 Gy x 4 & - 40 Gy: 10 Gy x 4 & \\
\hline & & - 36 Gy: 12 Gy x 3 & - 39 Gy: 13 Gy x 3 & - 39 Gy: 13 Gy x 3 & \\
\hline & & -30 Gy: 15 Gy x 2 & - 36 Gy: 12 Gy x 3 & & \\
\hline & & -30 Gy: 10 Gy x 3 & - 30 Gy: 10 Gy x 3 & & \\
\hline & & -27 Gy: 9 Gy x 3 & & & \\
\hline Dose per fraction (Gy) & $15(9-15)$ & $15(9-15)$ & 15 (9-15) & $15(10-15)$ & 0,026 \\
\hline
\end{tabular}

We performed a univariate analysis to identify prognostic factors of local control : factors included in the univariate analysis were : target diameter, GTV, PTV, total dose, dose per fraction, number of fractions and session length. The results are presented in Table 4 and

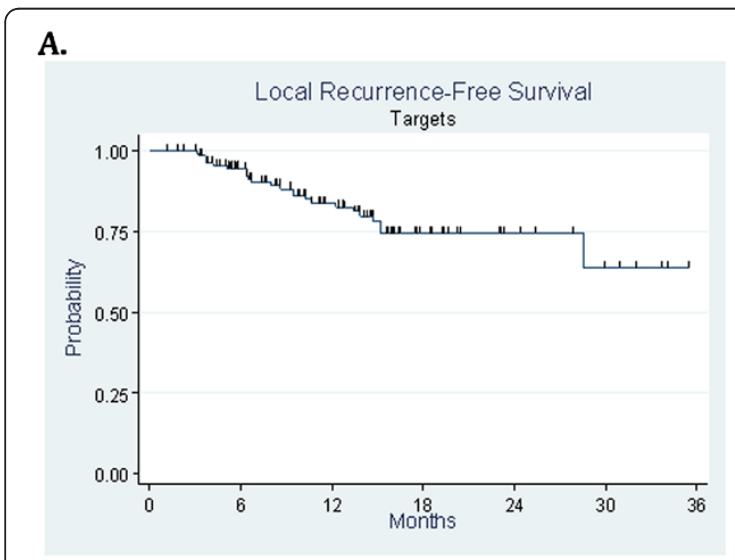

B.

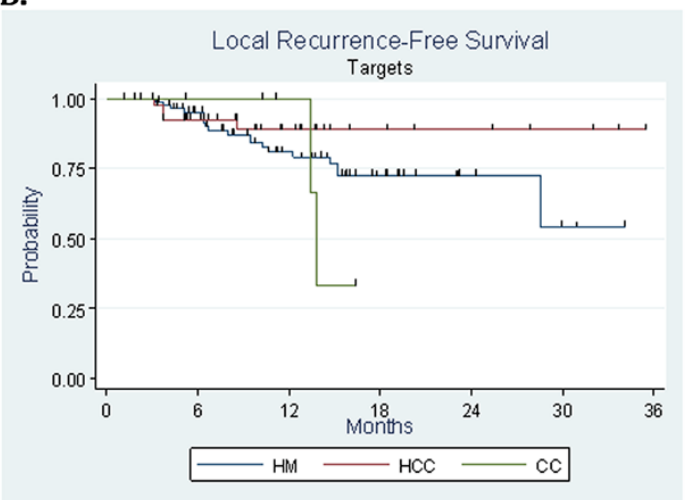

Figure 1 Local recurrence-free survival by target $(A)(n=153)$ and according to type of lesion (B).
Figure 2. Accordingly, PTV appeared to be linked to local control Figure $3(\mathrm{p}=0.014)$.

Median time to local recurrence in the target when the dose was less than $45 \mathrm{~Gy}$, or when the dose per fraction was less than $15 \mathrm{~Gy}$, was 28.6 months. Median time to recurrence with higher doses was not reached $(\mathrm{p}=0.019)$. The recurrence rate for tumors with PTV $>200 \mathrm{cc}$ was $33.3 \%$ compared to $13 \%$ when the volume was smaller $(\mathrm{p}=0.014)$.

\section{Discussion}

\section{Hepatocellular carcinoma}

We observed a local control rate at one and two years of $90.5 \%$. In other series in the literature, rates of local control vary from $65 \%$ to $100 \%$ (Table 5). The local control rate is $100 \%$ for the four HCC and one CC

Table 4 Univariate analysis of local control at one and two years per target $(n=153)$

\begin{tabular}{|c|c|c|c|}
\hline & $\begin{array}{l}\text { Local control per } \\
\text { target at } 1 \text { year }(\%)\end{array}$ & $\begin{array}{l}\text { Local control per } \\
\text { target at } 2 \text { years (\%) }\end{array}$ & $\mathrm{p}^{*}$ \\
\hline \multicolumn{4}{|c|}{ Total dose } \\
\hline$=45 \mathrm{~Gy}$ & $92.3(82.1-96.8)$ & $79.1(61.6-89.3)$ & \\
\hline$<45$ Gy & $72.0(56.4-82.8)$ & $66.5(50.3-78.5)$ & 0.019 \\
\hline \multicolumn{4}{|c|}{ Target diameter } \\
\hline$>50 \mathrm{~mm}$ & $74.6(54.6-86.8)$ & $63.0(39.8-79.3)$ & \\
\hline$<50 \mathrm{~mm}$ & $87.5(77.9-93.1)$ & $78.8(65.9-87.3)$ & 0.019 \\
\hline \multicolumn{4}{|c|}{ GTV volumes } \\
\hline$>100 \mathrm{cc}$ & $81.8(58.5-92.8)$ & $62.3(31.0-82.6)$ & \\
\hline$<100 \mathrm{cc}$ & $84.4(74.9-90.5)$ & $76.8(64.9-85.0)$ & 0.063 \\
\hline \multicolumn{4}{|c|}{ PTV volumes } \\
\hline$>200 \mathrm{cc}$ & $72.6(50.3-86.2)$ & $59.9(35.3-77.7)$ & \\
\hline$<200 \mathrm{cc}$ & $87.2(78.0-92.8)$ & $79.0(66.7-87.2)$ & 0.014 \\
\hline
\end{tabular}




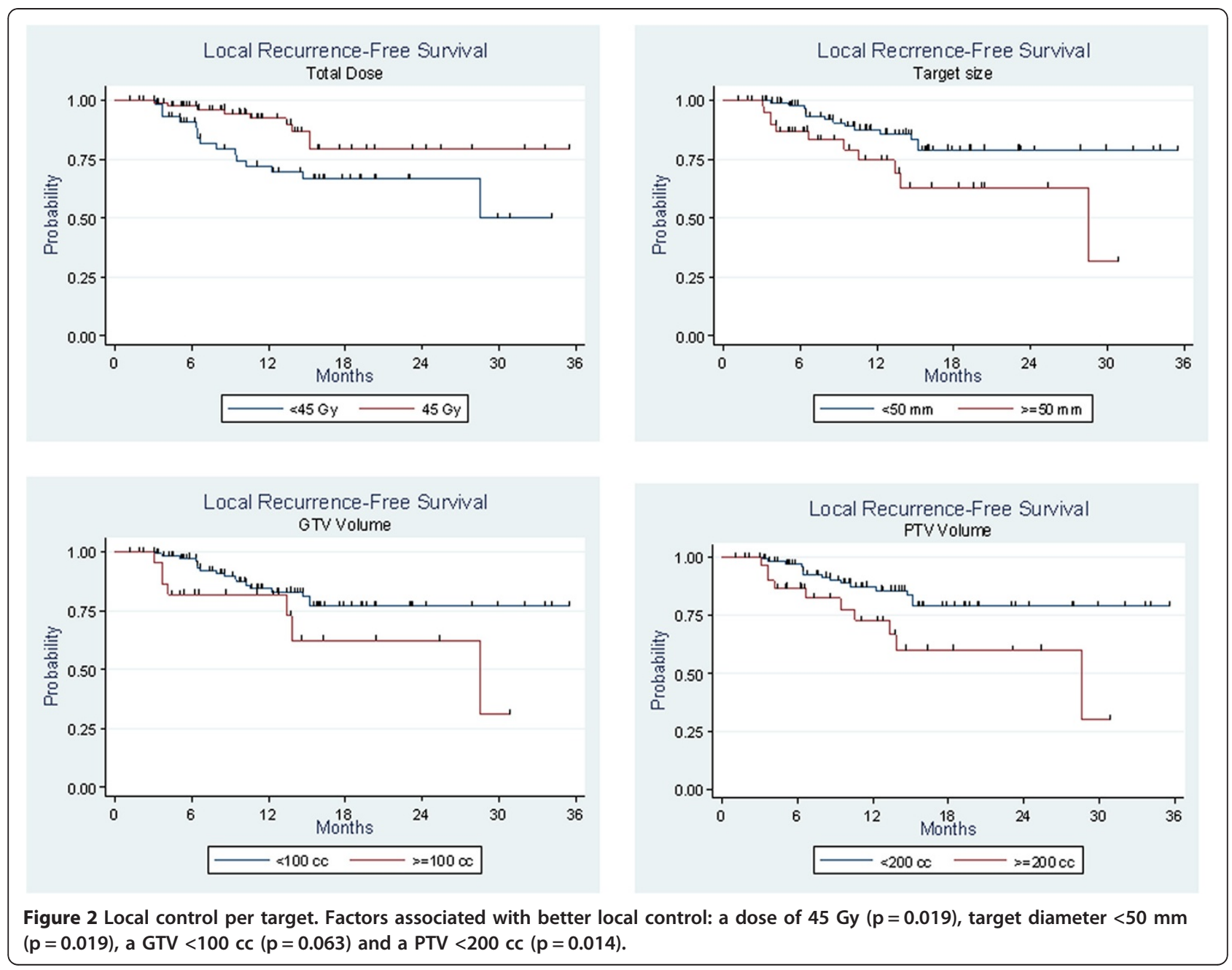

in the study of Wulf et al. [6]. The study by Choi et al. found a local control of $71.9 \%$ at a median follow-up of 10.5 months [7]. SBRT for HCC has found a role and been studied as a local salvage treatment after

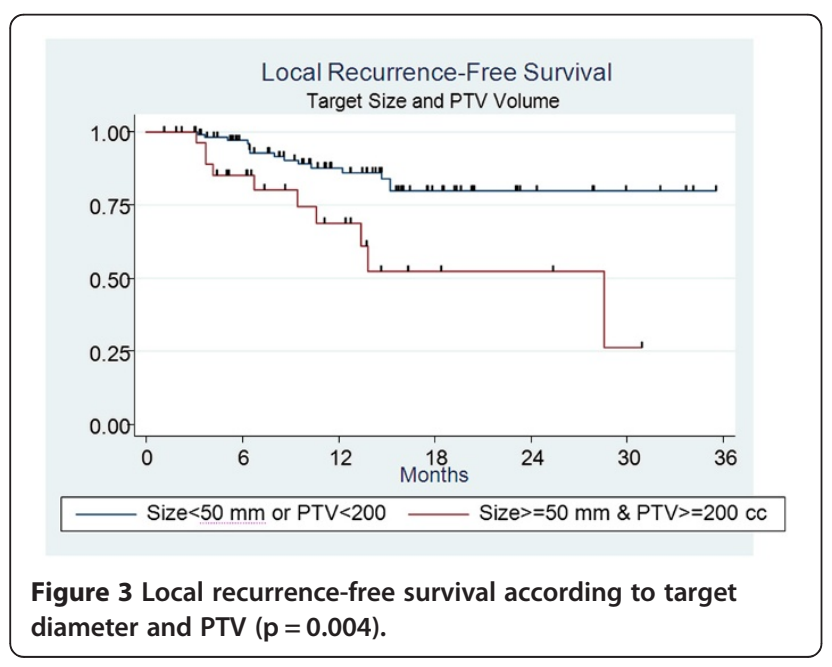

incomplete transarterial chemoembolization [8], as a bridge towards transplantation [9] or for recurrence treatment [10]. Each study found SBRT to be both a feasible and promising treatment for patient without any other treatment option.

\section{Cholangiocarcinoma}

Data on cholangiocarcinoma treated with SBRT is scarce. A study published by Kopek et al. [11] reported the results of SBRT for 27 patients with unresectable cholangiocarcinoma. 45 Gy were administered in three fractions. With a median follow-up of 5.4 years, the median progression-free survival and overall survival were 6.7 and 10.6 months respectively. Another study found similar interesting results with a one-year localcontrol rate of $100 \%$ [12]. However these studies had a limited number of patients. Their results are comparable to the efficacy of fractionated chemoradiotherapy for these poor-prognosis patients. SBRT could however be easier and faster to perform with less toxicity for the patient. 
Table 5 Published studies of stereotactic radiation therapy for hepatic lesions

\begin{tabular}{|c|c|c|c|c|c|c|c|c|}
\hline Study & No. of lesions & $\begin{array}{l}\text { No. of } \\
\text { patients }\end{array}$ & $\begin{array}{l}\text { Total } \\
\text { dose (Gy) }\end{array}$ & $\begin{array}{l}\text { No. of } \\
\text { fractions }\end{array}$ & $\begin{array}{l}\text { Lesion volume/ } \\
\text { Lesion size (medians) }\end{array}$ & $\begin{array}{l}\text { Post-treatment } \\
\text { period median } \\
\text { in months }\end{array}$ & $\begin{array}{l}\text { Local control } \\
\text { at } 1 \text { and } 2 \text { years }\end{array}$ & Comments \\
\hline \multirow[t]{2}{*}{ Blomgren et al. 1998 [20] } & $\mathrm{HCC}$ and $C C(n=20)$ & 41 & 30 & $2-3$ & $22 \mathrm{cc} /-$ & 11 & $100 \%$ overall control & Retrospective \\
\hline & $\mathrm{HM}(\mathrm{n}=21)$ & & & & $24 \mathrm{cc} /-$ & & $95 \%$ overall control & \\
\hline \multirow[t]{2}{*}{ Herfarth et al. 2001 [13] } & $\mathrm{HCC}+\mathrm{CC}(\mathrm{n}=4)$ & 37 & $14-26$ & 1 & $10 \mathrm{cc} /-$ & - & $67 /-$ & Phase $\mid / \|$ \\
\hline & $\mathrm{HM}(\mathrm{n}=56)$ & & & & & & & \\
\hline \multirow[t]{2}{*}{ Fuss et al. 2004 [21] } & $\mathrm{HCC}(n=1)$ & 15 & 36 & $3-6$ & $56 \mathrm{cc} /-$ & 6.5 & 94/- & Retrospective \\
\hline & $\mathrm{HM}(\mathrm{n}=17)$ & & & & & & & \\
\hline \multirow[t]{2}{*}{ Schefter et al. 2005 (27) } & $\mathrm{HM}(\mathrm{n}=18)$ & 18 & $36-60$ & 3 & $18 \mathrm{cc} /-$ & - & - & Phase I \\
\hline & & & & & & & & Body Frame \\
\hline \multirow[t]{4}{*}{ Mendez et al. 2006 [22] } & $\mathrm{HCC}(n=11)$ & 25 & $25-37.5$ & $3-5$ & $22 \mathrm{cc} / 32 \mathrm{~mm}$ & $12.9(1.1-322)$ & $94 / 82$ & Phase I/II \\
\hline & & & & & & & 75/75 (HCC) & Body Frame \\
\hline & $\mathrm{HM}(\mathrm{n}=34)$ & & & & & & $100 / 86$ & \\
\hline & & & & & & & $(\mathrm{HM})$ & \\
\hline \multirow[t]{2}{*}{ Wulf et al. 2006 [6] } & $\mathrm{HCC}+\mathrm{CC}(\mathrm{n}=5)$ & 44 & $21-36$ & $1-3$ & - & 15 & $92 / 66$ & Phase I \\
\hline & $\mathrm{HM}(n=39)$ & & & & & & & Body Frame \\
\hline \multirow[t]{2}{*}{ Hoyer et al. 2006 [23] } & HM CRC $(n=44)$ & 64 & 45 & 3 & -135 & 4.5 years & $-/ 79$ & Phase II \\
\hline & & & & & & & & Body Frame \\
\hline \multirow[t]{2}{*}{ Kavanagh et al. 2006 [24] } & $\mathrm{HM}(\mathrm{n}=36)$ & 36 & 60 & 3 & $14 \mathrm{cc} / 6$ & 19 & $93 \%$ at 18 months & Phase I/II \\
\hline & & & & & & & & Body Frame \\
\hline \multirow[t]{2}{*}{ Katz et al. 2007 [25] } & $\mathrm{HM}(\mathrm{n}=174)$ & 69 & $30-55$ & $7-20$ & $9.9 \mathrm{cc} / 27 \mathrm{~mm}$ & 14.5 & $76 / 57$ & Retrospective \\
\hline & & & & & & & & Exac Trac \\
\hline \multirow[t]{2}{*}{ Tse et al. 2008 [26] } & $\mathrm{HCC}+\mathrm{CC}(\mathrm{n}=31+10)$ & 41 & $24-54$ & 6 & $173 c c$ & $17.6(10.8-39.2)$ & $65 \%$ & Phase I \\
\hline & & & & & & & & $\overline{\text { Respiration control }}$ \\
\hline \multirow[t]{2}{*}{ Choi et al. 2008 [7] } & HCC $(n=32$. including 9 PT) & 31 & $30-39$ & 3 & $25 \mathrm{cc} /-$ & $10.5(2-18.5)$ & $71.9 \%$ at the median & Retrospective \\
\hline & & & & & & & of 10.5 months & $\overline{C y b e r K n i f e}$ \\
\hline Rusthoven et al. 2009 [15] & $\mathrm{HM}(\mathrm{n}=63)$ & 47 & 60 & 3 & $15 \mathrm{cc} / 27 \mathrm{~mm}$ & 16 & $95 / 92$ & Phase $1 / \|$ \\
\hline \multirow[t]{2}{*}{ Lee et al. 2009 [27] } & $\mathrm{HM}(\mathrm{n}=68)$ & 68 & $27-60$ & 6 & $75.2 \mathrm{cc} /-$ & 10.8 & $71 /-$ & Phase I \\
\hline & & & & & & & & $\overline{\text { Respiration control }}$ \\
\hline \multirow[t]{2}{*}{ Ambrosino et al. 2009 [1] } & $\mathrm{HM}(\mathrm{n}=27)$ & 27 & $25-60$ & 3 & $69 \mathrm{cc} /-$ & $13(6-16)$ & $85.2 \%$ overall control & Retrospective \\
\hline & & & & & & & & CyberKnife \\
\hline \multirow[t]{2}{*}{ Goodman et al. 2009 [3] } & $\mathrm{HCC}+\mathrm{CC}(\mathrm{n}=7)$ & 26 & $18-30$ & 1 & $33 \mathrm{cc} /-$ & $17.3(2-55)$ & $77 /-$ & Phase I \\
\hline & $\mathrm{HM}(\mathrm{n}=19)$ & & & & & & & CyberKnife \\
\hline Van der Pool et al. 2010 [4] & HM CRC $(n=31)$ & 20 & 37.5 & 3 & $-/ 23 \mathrm{~mm}$ & $26(6-57)$ & $-/ 74$ & Retrospective \\
\hline
\end{tabular}


Table 5 Published studies of stereotactic radiation therapy for hepatic lesions (Continued)

\begin{tabular}{|c|c|c|c|c|c|c|c|c|}
\hline & & & & & & & & Body Frame \\
\hline \multirow[t]{2}{*}{ Cardenes et al. 2010 [28] } & HCC $(n=25$. including 3 PT) & 17 & $36-48$ & 3 & $34 \mathrm{cc} / 40 \mathrm{~mm}$ & $24(10-42)$ & $100 \%$ & Phase I \\
\hline & & & & & & & & CyberKnife \\
\hline \multirow[t]{5}{*}{ Present study 2010} & 153 & 120 & $27-45$ & $2-4$ & $73 \mathrm{cc} / 48 \mathrm{~mm}$ & $15(12-18)$ & $80.4 / 72.5$ & Retrospective \\
\hline & HCC $(n=48$. including 3 PT) & 42 & $27-45$ & $2-3$ & $87 \mathrm{cc} / 48 \mathrm{~mm}$ & 13.7 & $90.5 / 90.5$ & CyberKnife \\
\hline & & & & & & & $73.3 / 67.4$ & \\
\hline & $\mathrm{HM}(\mathrm{n}=99)$ & 72 & $30-45$ & $3-4$ & $54 \mathrm{cc} / 47 \mathrm{~mm}$ & 15.5 & $100 /-$ & \\
\hline & $C C(n=6)$ & 6 & $39-45$ & $3-4$ & $208 \mathrm{cc} / 65 \mathrm{~mm}$ & 11 & & \\
\hline
\end{tabular}

HCC: hepatocarcinoma, HM: hepatic metastases, CC: intrahepatic cholangiocarcinoma, PT: portal thrombosis, CRC: colorectal cancer. 


\section{Metastases}

Regarding metastatic hepatic lesions in the literature, the median follow-up ranges from six to 54 months. The local control rate varies between $82 \%$ and $100 \%$. At one and two years, actuarial control rates range from $71 \%$ to $100 \%$ and from $64 \%$ to $86 \%$ The only prognostic factor found is the dose, tumors receiving a lower dose having a poorer local control.

\section{Total dose as a major prognostic factor}

One of the first prospective studies using stereotactic radiotherapy as a single fraction with doses of 14-26 Gy for the treatment of hepatic tumors, including HCC and metastases, was conducted by Herfarth et al. [13]. The actuarial local control rates were $75 \%, 71 \%$, and $67 \%$ at six-, 12-, and 18-months respectively. Updating these results yielded a local control rate of $66 \%$ at 18 months after a single fraction of 22 Gy [14]. The authors showed that the reduction in tumor volume may be delayed after a single irradiation dose; eight of the 17 patients with stable disease at the first evaluation achieved a complete or partial response at last follow-up. More recently, Ambrosino et al. published their preliminary results of SBRT by CyberKnife for unresectable hepatic lesions in 27 patients [1]. They obtained disease control in 74.1\% of cases. The latest study to our knowledge was by Van der Pool et al. [4], reporting a local control rate of $74 \%$ at two years, with the Body Frame system, after three sessions of $12.5 \mathrm{~Gy}$. Our results appear quite similar to these studies, local control rates at one and two years being $73.3 \%$ and $67.4 \%$, respectively. The prescription dose is very heterogeneous in these studies, making comparison of the results difficult. The importance of the dose in the treatment of hepatic metastases has already been suggested. In the study by Herfarth, progression was observed in 12 of 55 tumors (22\%) [13]. The difference in local tumor control between the group receiving 20 to $26 \mathrm{~Gy}$, compared with the group receiving 14 to $20 \mathrm{~Gy}$, was statistically significant ( $\mathrm{p}<0.001)$. The diameter and the volume of the GTV and the PTV were identified in our series as prognostic factors of local control. The influence of the tumor size remains controversial in the literature. According to Rusthoven et al., size plays a role in local control: lesions less than $3 \mathrm{~cm}$ have a local control rate at two years of $100 \%$, compared to $77 \%$ for lesions greater than $3 \mathrm{~cm}(\mathrm{p}=0.0015)$ [15]. In other series, stratification by size reveals no significant difference in local control between lesions larger than $15 \mathrm{~cm}^{3}$ compared with lesions less than $15 \mathrm{~cm}^{3}$ in patients treated with doses above 20 Gy [13].

In the literature, the treatment technique, dose, and fractionation used vary from one study to the other. The doses delivered range from $30 \mathrm{~Gy}$ in a single fraction to 54 Gy in six fractions of 9 Gy $[6,7,16]$. It has been demonstrated that there is a dose-response relationship for HCC with non-stereotactic conformal hepatic irradiation with an increased response rate as the dose increases $[17,18]$. The same relationship holds when reproduced using the milimetric tracking accuracy of CyberKnife. Our treatment regimen enables delivering a total dose of 45 Gy in three fractions of 15 Gy. According to the quadratic linear model, the equivalent of this dose in conventional fractionation of 2 Gy for an alpha/ beta ratio of 10 Gy would be 112.5 Gy. Regarding fractionation, the regimens with a single session seem a little less effective in terms of local control, especially those using a low dose per fraction [13,17]. A recent study reviewed 141 patients treated with hepatic and pulmonary stereotactic radiation therapy, without distinction, in order to find predictive factors of local control [16]. There were 246 lesions (165 lung cancers and 81 patients with hepatic lesions). The factors found in that analysis were also, as in our series, the delivered dose $(\mathrm{p}<0.001)$ and a tendency for the GTV $(\mathrm{p}=0.064)$ in multivariate analysis. In another study, the team of Wada et al. demonstrated a role for target size in 24 patients treated for 42 lesions in both lung and hepatic locations [19]. A lesion of less than $3 \mathrm{~cm}$ in diameter was associated with better local control $(p=0.0022)$. While many studies show the interest of SBRT for liver tumors [20-28], most of them are retrospective or with a limited number of patients. Dose regimens and delivery techniques vary to a great extent between each of them. A multicentric, randomized trial comparing SBRT to surgery could be of great interest in this context.

\section{Conclusion}

Our experience including 120 patients, reported in this work, is to our knowledge the largest series in the literature. Factors limiting the effectiveness of this treatment presented in this work are: lesion diameter, the volume of the tumor and of the PTV. A total dose of 45 Gy and 15 Gy per fraction is necessary for maximum efficiency. There is a certain dose-response relationship for $\mathrm{HCC}$, as well as with HM, prompting a high dose level as possible.

\section{Competing interests \\ Pr Eric Lartigau is a consultant for ACCURAY.}

Authors' contributions

SD and XM conceived the study. SD collected data. SD and JEB drafted the manuscript. XM, IF, HJ, TL, CDV and EL participated in coordination and helped to draft the manuscript. AK performed the statistical analyses. EL provided mentorship and edited the manuscript. All authors have read and approved the final manuscript.

\section{Acknowledgements}

The authors acknowledge S. Marchant for her valuable contribution during the conduct of this study. 


\section{Author details}

${ }^{1}$ Academic Radiation Oncology Department \& University Lille II, CLCC Oscar Lambret, 3 rue Frederic Combemale, BP 307, Lille cedex 59 020, France. ${ }^{2}$ Methodology and Biostatistics Unit, CLCC Oscar Lambret, 3 rue Frederic Combemale, BP 307, Lille cedex 59 020, France. ${ }^{3}$ Department of Radiology, CLCC Oscar Lambret, 3 rue Frederic Combemale, BP 307, Lille cedex 59 020, France.

Received: 26 March 2012 Accepted: 26 September 2012

Published: 10 October 2012

\section{References}

1. Ambrosino G, Polistina F, Costantin G, et al: Image-guided robotic stereotactic radiosurgery for unresectable liver metastases: preliminary results. Anticancer Res 2009, 29:3381-3384.

2. Cárdenes HR: Role of stereotactic body radiotherapy in the management of primary hepatocellular carcinoma. Rationale, technique and results. Clin Transl Oncol 2009, 11:276-283.

3. Goodman KA, Wiegner EA, Maturen KE, et al: Dose-escalation study of single-fraction stereotactic body radiotherapy for liver malignancies. Int J Radiat Oncol Biol Phys 2010, 78:486-493

4. van der Pool AEM, Méndez Romero A, Wunderink W, et al: Stereotactic body radiation therapy for colorectal liver metastases. Br J Surg 2010, 97:377-382.

5. Bruix J, Sherman M, Llovet JM, et al: Clinical management of hepatocellular carcinoma. Conclusions of the Barcelona-2000 EASL conference. European Association for the Study of the Liver. $J$ Hepatol 2001, 35:421-430

6. Wulf J, Hädinger $U$, Oppitz $U$, et al: Stereotactic radiotherapy of targets in the lung and liver. Strahlenther Onkol 2001, 177:645-655.

7. Choi BO, Choi IB, Jang HS, et al: Stereotactic body radiation therapy with or without transarterial chemoembolization for patients with primary hepatocellular carcinoma: preliminary analysis. BMC Cancer. 2008, 8:351

8. Kang J-K, Kim M-S, Cho CK, et al: Stereotactic body radiation therapy for inoperable hepatocellular carcinoma as a local salvage treatment after incomplete transarterial chemoembolization. Cancer 2012, [published online ahead of print May 8 2012]. Accessed October 1, 2012.

9. O'Connor JK, Trotter J, Davis GL, et al: Long-term outcomes of stereotactic body radiation therapy in the treatment of hepatocellular cancer as a bridge to transplantation. Liver Transp/ 2012, 18:949-954.

10. Huang $W-Y$, Jen $Y-M$, Lee $M-S$, et al: Stereotactic body radiation therapy in recurrent hepatocellular carcinoma. Int J Radiat Oncol Biol Phys 2012, 84:355-361.

11. Kopek N, Holt MI, Hansen AT, Høyer M: Stereotactic body radiotherapy for unresectable cholangiocarcinoma. Radiother Oncol 2010, 94:47-52.

12. Barney BM, Olivier KR, Miller RC, Haddock MG: Clinical outcomes and toxicity using Stereotactic Body Radiotherapy (SBRT) for advanced cholangiocarcinoma. Radiat Oncol 2012, 7:67.

13. Herfarth KK, Debus J, Lohr F, et al: Stereotactic single-dose radiation therapy of liver tumors: results of a phase I/II trial. J Clin Oncol 2001, 19:164-170.

14. Herfarth KK, Debus J: Stereotactic radiation therapy for liver metastases. Chirurg 2005, 76:564-569.

15. Rusthoven $\mathrm{KE}$, Kavanagh $\mathrm{BD}$, Cardenes $\mathrm{H}$, et al: Multi-institutional phase I/II trial of stereotactic body radiation therapy for liver metastases. J Clin Oncol 2009, 27:1572-1578.

16. McCammon R, Schefter TE, Gaspar LE, et al: Observation of a dose-control relationship for lung and liver tumors after stereotactic body radiation therapy. Int J Radiat Oncol Biol Phys 2009, 73:112-118.

17. Dawson LA, McGinn CJ, Normolle D, et al: Escalated focal liver radiation and concurrent hepatic artery fluorodeoxyuridine for unresectable intrahepatic malignancies. J Clin Oncol 2000, 18:2210-2218.

18. Park HC, Seong J, Han KH, et al: Dose-response relationship in local radiotherapy for hepatocellular carcinoma. Int J Radiat Oncol Biol Phys 2002, 54:150-155.

19. Wada $H$, Takai $Y$, Nemoto $K$, Yamada S: Univariate analysis of factors correlated with tumor control probability of three-dimensional conformal hypofractionated high-dose radiotherapy for small pulmonary or hepatic tumors. Int J Radiat Oncol Biol Phys 2004, 58:1114-1120.
20. Blomgren H, Lax I, Näslund I, Svanström R: Stereotactic high dose fraction radiation therapy of extracranial tumors using an accelerator: clinical experience of the first thirty-one patients. Acta Oncol 1995, 34:861-870.

21. Schefter TE, Kavanagh BD, Timmerman RD, et al: A phase I trial of stereotactic body radiation therapy (SBRT) for liver metastases. Int $\mathrm{J}$ Radiat Oncol Biol Phys 2005, 62:1371-1378.

22. Méndez Romero A, Wunderink W, Hussain SM, et al: Stereotactic body radiation therapy for primary and metastatic liver tumors: A single institution phase i-ii study. Acta Oncol 2006, 45:831-837.

23. Hoyer M, Roed $H$, Traberg Hansen $A$, et al: Phase II study on stereotactic body radiotherapy of colorectal metastases. Acta Oncol 2006, 45:823-830.

24. Kavanagh BD, Schefter TE, Cardenes HR, et al: Interim analysis of a prospective phase I/II trial of SBRT for liver metastases. Acta Oncol 2006, 45:848-855

25. Katz AW, Carey-Sampson M, Muhs AG, et al: Hypofractionated stereotactic body radiation therapy (SBRT) for limited hepatic metastases. Int J Radiat Oncol Biol Phys 2007, 67:793-798.

26. Tse RV, Hawkins M, Lockwood G, et al: Phase I study of individualized stereotactic body radiotherapy for hepatocellular carcinoma and intrahepatic cholangiocarcinoma. J Clin Oncol 2008, 26:657-664.

27. Lee MT, Kim JJ, Dinniwell R, et al: Phase I study of individualized stereotactic body radiotherapy of liver metastases. J Clin Oncol 2009, 27:1585-1591

28. Cárdenes HR, Price TR, Perkins SM, et al: Phase I feasibility trial of stereotactic body radiation therapy for primary hepatocellular carcinoma. Clin Transl Oncol 2010, 12:218-225.

doi:10.1186/1748-717X-7-166

Cite this article as: Dewas et al:: Prognostic factors affecting local control of hepatic tumors treated by stereotactic body radiation therapy. Radiation Oncology 2012 7:166.

\section{Submit your next manuscript to BioMed Central and take full advantage of:}

- Convenient online submission

- Thorough peer review

- No space constraints or color figure charges

- Immediate publication on acceptance

- Inclusion in PubMed, CAS, Scopus and Google Scholar

- Research which is freely available for redistribution 